\title{
Efficacy of fungicide 'Kavach' against Beauveria bassiana L. in silkworm Bombyx mori L.
}

\author{
V. Rajagopal ${ }^{1}$, H.L. Ramesh ${ }^{2}$, V.N. Yogananda Murthy ${ }^{3 *}$ and K.N. Ninge Gowda ${ }^{4}$ \\ ${ }^{1}$ Department of Chemistry, V.V. Pura College of Science, K.R. Road, Bangalore-560004 (Karnataka), INDIA \\ ${ }^{2}$ Department of Sericulture, V.V. Pura College of Science, K.R. Road, Bangalore-560004 (Karnataka), INDIA \\ ${ }^{3}$ Department of Life Sciences, Ganga Kaveri Institute of Science and Management, Dr. Rajkumar Road, \\ Rajajinagar, Bangalore-560021 (Karnataka), INDIA \\ ${ }^{4}$ Department of Fashion and Apparel Technology, Bangalore University, Bangalore-560001 (Karnataka), INDIA \\ *Corresponding author. E-mail: yoga16@rediffmail.com
}

Received: December 29, 2013; Revised received: January 29, 2014; Accepted: February 20, 2014

\begin{abstract}
Silkworm Bombyx mori L. is prone to be attacked by pathogen and more notably Beauveria bassiana L. Bed disinfectant Kavach was inoculated in different dosages (0.2\%-1.6\%) to IV and $\mathrm{V}$ instar silkworms of both bivoltine and cross breeds. Potency of disinfectant was assessed for the parameters such as survivability, larval duration, physiological, chemo and bio-assay tests. It was revealed that, bivoltine $\left(\mathrm{NB}_{4} \mathrm{D}_{2}\right)$ silkworms were highly susceptible to diseases compared to cross breeds $\left(\mathrm{PMxNB}_{4} \mathrm{D}_{2}\right)$. In bivoltine silkworms, survivability was found to be $61.15 \%$ at $1.6 \%$ of Kavach, when dusted twice during IV and V instar and crossbreed silkworms exhibited better resistance of $63.10 \%$ with the same treatments. Kavach treated silkworms showed decreased larval duration compared to control worms. Crossbreed silkworms were capable of maintaining high level of soluble proteins in spite of infection on $3^{\text {rd }}$ day $(17.40 \%), 4^{\text {th }}$ day $(20.50 \%)$ and $5^{\text {th }}$ day $(21.55 \%)$ whereas in bivoltine silkworms soluble protein level was brought down on $3^{\text {rd }}$ day $(19.30 \%), 4^{\text {th }}$ day $(22.40 \%)$ and $5^{\text {th }}$ day $(23.40 \%)$. Total soluble sugars varied from third day till fifth day in both the races. Kavach dusted twice at $1 \%$ proved to be very useful in the improvement of various commercial cocoons characters.
\end{abstract}

Keywords: Beauveria bassiana, Bombyx mori, Commercial characters, Kavach, Silkworm

\section{INTRODUCTION}

Sericulture is an applied branch of science, multi-disciplinary in nature and is rural oriented, practiced more prominently in the tropical countries (Singhvi et al., 1996; Seidavi et al., 2005; Dandin, 2008; Nagaraju, 2008; Ahmed and Rajan, 2011; Anitha, 2011). Mulberry silkworm $B$. mori is of great economic importance for many silk producing countries in the world (Krishnaswami et al., 1992). Karnataka is the hub of sericulture activities, pioneer in silk production and occupies a prime position in India's total silk production. Karnataka is blessed with salubrious environmental conditions and farmers hailing from different strata of society have been practicing sericulture throughout the year since time immemorial and this makes it highly susceptible to pathogens and hence occurrence of diseases is the rule of nature (Samson et al., 1998).

Silkworm is prone to attacked by several diseases due to biotic and abiotic factors with considerable toll. Four silkworm diseases namely Grasserie (viral), Flacherie (bacterial), Muscardine (fungal) and Pebrine (protozoan) are common in China and India. These diseases caused heavy damage to silkworm crops in the past and in India more than 40 percent of crop losses still occur due to these diseases (Veeranna, 1999). Due to domestication of silkworms since several decades, silkworms are most susceptible to different diseases caused by various pathogens. White muscardine is an infectious disease caused by pathogenic fungi $B$. bassiana in all seasons and regions in India (Chandrasekaran and Nataraju, 2008). The intensity of the disease is very high in winter and rainy seasons. Several investigators have made an attempt to prevent the occurrence of this disease by using different concentrations of fungicide (Subba Rao et al., 1992; Baig et al., 1993; Isaiarasu et al., 2011). Keeping the above in view, main objective of the present investigation is to prevent/control Beauveria bassiana, increase silkworm cocoon yield and to improve the commercial characters of cocoon using Kavach as a fungicide.

\section{MATERIALS AND METHODS}

Collection, isolation and culture of fungus: Fungal spores collected from white muscardine infected silkworm cadavers and Photo Dextrose Agar (PDA) is used as media (Pant et al., 2002) for fungal spores culture. Efficiency of the fungicide invitro will be 
tested against $B$. bassiana at different concentrations viz., $0.05 \%, 0.125 \%$ and $0.25 \%$ (Chinnaswamy and Devaiah, 1986). Whatman No. 40 filter paper discs were dipped in the above concentration of fungicides and placed in petri plates containing spore load of one lakh spore $/ \mathrm{cm}^{3}$ of the PDA. Two discs per plate were placed equidistant, replicated thrice. Zones of inhibition were measured after six days. To test the rearing efficiency, two silkworm races namely, cross breed $\left(\mathrm{PMxNB}_{4} \mathrm{D}_{2}\right)$ and bivoltine $\left(\mathrm{NB}_{4} \mathrm{D}_{2}\right)$ were used. Disease free layings obtained from National Silkworm Seed Project (NSSP), Bangalore were used. Rearing experiments were conducted by adopting appropriate cellular rearing techniques (Krishnaswami et al., 1970; Krishnaswami, 1978; 1990; Benchamin and Nagaraj, 1987). Spore suspension was prepared and spore counts were done by haemocytometer. Silkworms out of third moult were inoculated with spores through topical application using automiser (Patil, 1993; Patil et al., 2001). Different concentrations of Kavach ranging from $0.2 \%-3.2 \%$ were prepared for the topical application of silkworm with Kaolin as a base material. Kavach applied at concentration of $0.2 \%, 0.4 \%, 0.6 \%, 0.8 \%, 1.0 \%, 1.2 \%$, $1.4 \%$ and $1.6 \%$. Different concentrations of Kavach were applied topically on inoculated worms at the following frequencies.

- Dusting once in an instar during IV and V instars.

- Dusting twice in an instar during IV and V instars with a duration of 24 hours.

- Dusting thrice in an instar during IV and V instars with a duration of 24 hours.

In each case, the first dusting was carried out after six hours of inoculation. Silkworm reared without any inoculation and without any topical application of Kavach constituted control I and silkworm inoculated without any topical application of Kavach constituted control II. As $100 \%$ mortality was recorded in control batch II, first one was considered as control. Physiological parameters viz., food ingested, efficiency percentage of conversion of digested food and growth rate were calculated by adopting standard procedure (Waldbauer, 1968). Total soluble proteins, total soluble sugars in haemolymph were estimated according to standard procedures. Proteins were measured by Lowry et al. (1951) method using Folin-phenol reagent. Total sugars were estimated by Plummer (1971) method using anthrone reagent. Larval duration and various commercial characteristics of cocoon were calculated using standard procedures (Sonwalkar, 1991).

Data analysis: One-way analysis of variance was used to test the significance of differences between mean values of independent observations. Comparisons were performed with WINSTAT statistical package to find significant differences between the different treatments.

\section{RESULTS AND DISCUSSION}

Results revealed the effect of topical application of Kavach on survivability, larval duration and commercial characteristics of bivoltine and cross breed silkworms inoculated with B. bassiana dusted (once, twice and thrice) during IV and V instars. Effect of fungicide Kavach at different concentrations on inoculated bivoltine and crossbreed silkworms resulted in lowering the incidence of infection at different rates. Treatment of larvae with Kavach during IV and V instars resulted in lowest fungal infection in both breeds with the given spore load. It is noticed that bivoltine silkworms had higher infection than crossbreeds.

Survivability: Different dosages of fungicide revealed difference in survival percentage of silkworms with the increase in concentration of fungicide in both bivoltine and crossbreed silkworm races. Least mortality was noticed at higher concentrations of fungicide and highest mortality at lower concentration of fungicide. Survivability was $61.15 \%$ at $1.6 \%$ when Kavach dusted twice during IV and V instars in bivoltine silkworms and in crossbreed silkworms it was $63.10 \%$ with same treatment conditions (Tables 1 and 2). Chinnaswamy (1983) and Anitha Peter (1989) have reported that, bivoltine races $\left(\mathrm{NB}_{4} \mathrm{D}_{2}, \mathrm{NB}_{7}, \mathrm{NB}_{18}, \mathrm{KA}\right)$ are highly susceptible compared to multivoltine (PM and HM). Soaf et al. (1994) have studied the comparative efficacy of a few fungicides and showed that Captan at 3\% treatment was most effective followed by Foltaf 3\%, which showed a mortality of $2.22 \%$ and $2.44 \%$ respectively due to infection of $B$. bassiana.

Larval duration: Larval stage is an active feeding part in the life cycle of $B$. mori and larval age considerably varied between control and fungicide treated worms (Figs.1 and 2). Kavach treated worms showed decreased larval duration (4hours to 24hours) compared to control worms. Silkworms maintained in control groups behaved normally and they were active and the movements are well coordinated without any disturbances during feeding. But, silkworms treated with lethal dosages of fungicide exhibited contractures, causing worms to roll over one another lose structure of skin and appearance of black spots on the body surface, omitting of gastric fluid and irregular excretion. Present results were in conformity with the findings of Devaiah et al. (1983), Subba Rao et al. (1992) and Baig et al. (1993). Fungicides inhibit acetyl cholinesterase activity in animals. Inhibition of acetyl cholinesterase in central nervous system blocks the transfer of impulse synapse has been set to be the major factor in death of animals (Soaf et al., 1994). Pant et al. (2002) opined that, lepidopteron larvae had more or less continuous feeders shortening of feed periods in larvae and decrease in final body weight.

Biochemical analysis: Due to infection of $B$. bassiana there is decline in haemolymph $\mathrm{pH}$ in bivoltine 


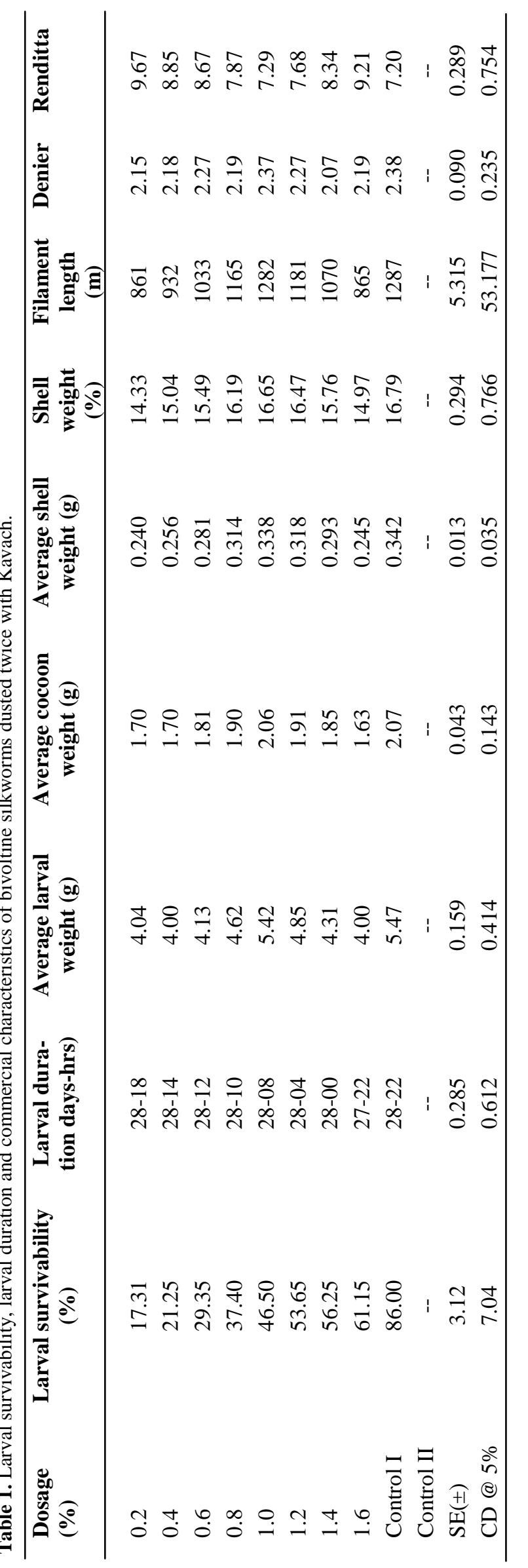

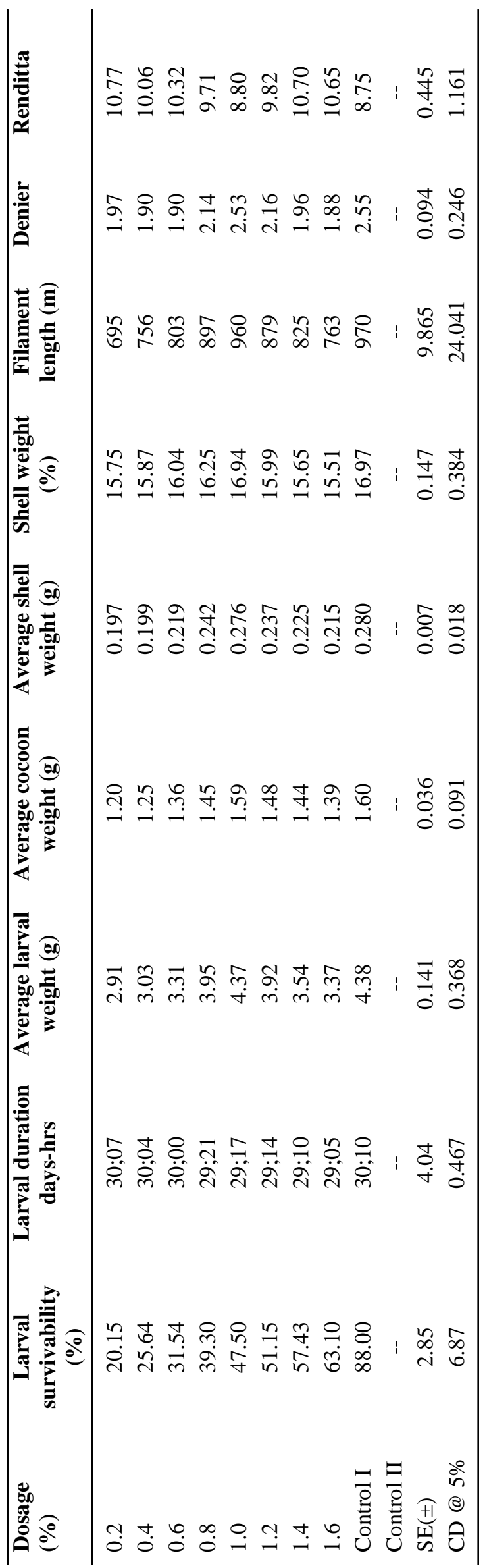


Table 3. $\mathrm{pH}$, soluble proteins and soluble sugars in the haemolymph of bivoltine silkworms inoculated and dusted twice with Kavach.

\begin{tabular}{lccccccccc}
\hline Dosage & \multicolumn{3}{c}{$\mathbf{p H}$} & \multicolumn{4}{c}{ Soluble proteins } & \multicolumn{3}{c}{ Soluble sugars } \\
\cline { 2 - 10 } & $\mathbf{3}^{\text {rd }} \mathbf{d a y}$ & $\mathbf{4}^{\text {th }} \mathbf{d a y}$ & $\mathbf{5}^{\text {th }} \mathbf{d a y}$ & $\mathbf{3}^{\text {rd }} \mathbf{d a y}$ & $\mathbf{4}^{\text {th }} \mathbf{d a y}$ & $\mathbf{5}^{\text {th }} \mathbf{d a y}$ & $\mathbf{3}^{\text {rd }} \mathbf{d a y}$ & $\mathbf{4}^{\text {th }} \mathbf{d a y}$ & $\mathbf{5}^{\text {th }}$ day \\
\hline 0.4 & 7.17 & 6.74 & 6.39 & 18.85 & 20.57 & 21.16 & 32.95 & 16.40 & 17.30 \\
1.0 & 7.12 & 6.80 & 6.47 & 19.15 & 22.20 & 22.74 & 33.80 & 15.60 & 16.95 \\
1.6 & 7.04 & 6.86 & 6.55 & 19.30 & 22.40 & 23.40 & 34.25 & 14.00 & 16.30 \\
Control & 6.95 & 6.78 & 6.67 & 19.70 & 23.35 & 24.65 & 35.90 & 13.30 & 15.10 \\
SE( \pm ) & 0.110 & 0.106 & 0.102 & 0.299 & 0.313 & 0.299 & 0.533 & 0.377 & 0.451 \\
CD@ 5\% & 0.289 & 0.278 & 0.267 & 0.784 & 0.820 & 0.782 & 1.395 & 0.985 & 1.180 \\
\hline
\end{tabular}

Table 4. $\mathrm{pH}$, soluble proteins and soluble sugars in the haemolymph of cross breed silkworms inoculated and dusted twice with Kavach.

\begin{tabular}{llllllllll}
\hline Dosage & \multicolumn{3}{c}{$\mathbf{p H}$} & \multicolumn{4}{c}{ Soluble proteins } & \multicolumn{3}{c}{ Soluble sugars } \\
\cline { 2 - 9 } & $\mathbf{3}^{\text {rd }}$ day & $\mathbf{4}^{\text {th }}$ day & $\mathbf{5}^{\text {th }}$ day & $\mathbf{3}^{\text {rd }}$ day & $\mathbf{4}^{\text {th }}$ day & $\mathbf{5}^{\text {th }}$ day & $\mathbf{3}^{\text {rd }} \mathbf{d a y}$ & $\mathbf{4}^{\text {th }}$ day & $\mathbf{5}^{\text {th }}$ day \\
\hline 0.4 & 7.12 & 6.44 & 6.20 & 16.55 & 19.10 & 19.70 & 29.80 & 16.00 & 16.60 \\
1.0 & 7.09 & 6.50 & 6.25 & 17.25 & 20.15 & 20.35 & 30.60 & 16.60 & 15.85 \\
1.6 & 7.04 & 6.54 & 6.31 & 17.40 & 20.50 & 21.55 & 31.60 & 14.00 & 15.05 \\
Control & 6.85 & 6.69 & 6.50 & 17.75 & 21.60 & 22.65 & 32.55 & 13.20 & 14.10 \\
SE( \pm ) & 0.105 & 0.101 & 0.098 & 0.268 & 0.289 & 0.268 & 0.502 & 0.357 & 0.428 \\
CD@ 5\% & 0.275 & 0.264 & 0.254 & 0.701 & 0.755 & 0.700 & 1.314 & 0.934 & 1.119 \\
\hline
\end{tabular}

Table 5. Food ingestion of IV and V instar bivoltine $\left(\mathrm{NB}_{4} \mathrm{D}_{2}\right)$ silkworms treated with Kavach dusted twice.

\begin{tabular}{lccccccc}
\hline Dosage & \multicolumn{3}{c}{ IV instar } & \multicolumn{4}{c}{ V instar } \\
\cline { 2 - 8 } & $\mathbf{1}^{\text {st }} \mathbf{d a y}$ & $\mathbf{2}^{\text {nd }} \mathbf{d a y}$ & $\mathbf{3}^{\text {rd }} \mathbf{d a y}$ & $\mathbf{2}^{\text {nd }} \mathbf{d a y}$ & $\mathbf{3}^{\text {rd }} \mathbf{d a y}$ & $\mathbf{4}^{\text {th }} \mathbf{d a y}$ & $\mathbf{5}^{\text {th }} \mathbf{d a y}$ \\
\hline 0.4 & 5.60 & 5.90 & 6.95 & 6.50 & 11.70 & 28.70 & 23.45 \\
1.0 & 5.85 & 6.25 & 7.35 & 7.45 & 12.40 & 30.15 & 24.95 \\
1.6 & 5.30 & 5.60 & 6.45 & 6.20 & 11.50 & 28.35 & 23.00 \\
Control & 6.20 & 6.50 & 7.55 & 7.85 & 12.50 & 30.35 & 24.90 \\
SE( \pm ) & 0.092 & 0.104 & 0.116 & 0.119 & 0.191 & 0.470 & 0.451 \\
CD @ 5\% & 0.241 & 0.273 & 0.304 & 0.312 & 0.501 & 1.229 & 1.180 \\
\hline
\end{tabular}

Table 6. Food conversion of IV and V instar bivoltine $\left(\mathrm{NB}_{4} \mathrm{D}_{2}\right)$ silkworms treated with Kavach dusted twice.

\begin{tabular}{|c|c|c|c|c|c|c|c|}
\hline \multirow[t]{2}{*}{ Dosage } & \multicolumn{3}{|c|}{ IV instar } & \multicolumn{4}{|c|}{$V$ instar } \\
\hline & $1^{\text {st }}$ day & $2^{\text {nd }}$ day & $3^{\text {rd }}$ day & $2^{\text {nd }}$ day & $3^{\text {rd }}$ day & $4^{\text {th }}$ day & $5^{\text {th }}$ day \\
\hline 0.4 & 4.45 & 4.90 & 5.25 & 4.55 & 8.85 & 17.60 & 16.65 \\
\hline 1.0 & 5.70 & 6.00 & 6.25 & 5.70 & 9.95 & 22.60 & 19.85 \\
\hline 1.6 & 4.20 & 4.60 & 5.10 & 4.40 & 8.70 & 17.25 & 17.00 \\
\hline Control & 5.95 & 6.25 & 6.70 & 5.85 & 10.40 & 22.75 & 20.30 \\
\hline $\mathrm{SE}( \pm)$ & 0.087 & 0.071 & 0.095 & 0.073 & 0.156 & 0.305 & 0.295 \\
\hline CD@5\% & 0.227 & 0.185 & 0.249 & 0.192 & 0.407 & 0.798 & 0.772 \\
\hline
\end{tabular}

$\left(\mathrm{NB}_{4} \mathrm{D}_{2}\right)$ and crossbreed $\left(\mathrm{PMxNB}_{4} \mathrm{D}_{2}\right)$. In both the races, haemolymph $\mathrm{pH}$ reached an acidic state indicating infection by fungus which sets in academia. Further, increased accumulation of metabolites in haemolymph of infected larvae may contribute some extent for declining of $\mathrm{pH}$ (Kusunoki and Watanabe, 1982). Results indicate that, due to infection by $B$. bassiana total soluble protein content is affected considerably and level was brought down in bivoltine silkworms $\left(\mathrm{NB}_{4} \mathrm{D}_{2}\right)$ whereas crossbreed silkworms
$\left(\mathrm{PMxNB}_{4} \mathrm{D}_{2}\right)$ are capable of maintaining high level of soluble protein contents in spite of infection. It is concluded that, infection by $B$. bassiana induces hypoproteinemia condition in infected larval haemolymph. Reduction in haemolymph protein may be a consequence of metabolism of protein and amino acid of larval haemolymph by developing pathogen and therefore haemolymph is diluted as far as protein content is concerned. Secondly, reduction in haemolymph is due to starvation (Tables 3 and 4). In 


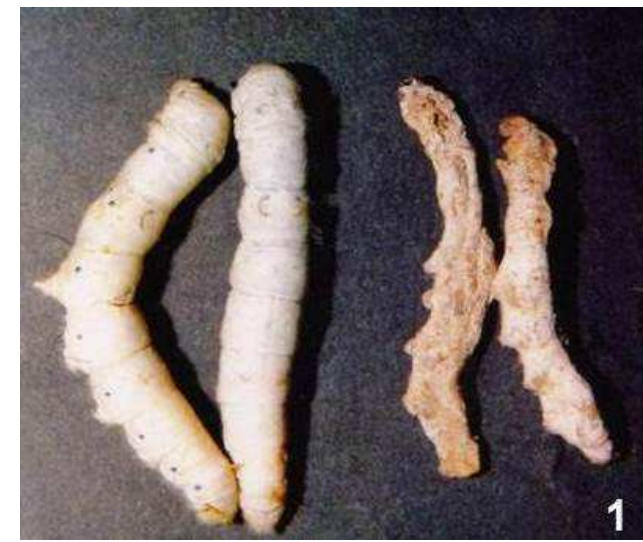

Fig. 1. Healthy and infected IV instar Cross Breed $\left(\mathrm{PMxNB}_{4} \mathrm{D}_{2}\right)$ silkworms.

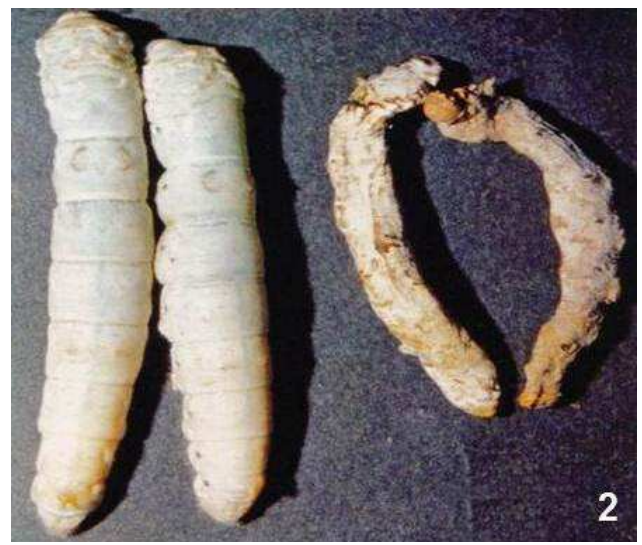

Fig. 2. Healthy and infected IV instar Bivoltine $\left(\mathrm{NB}_{4} \mathrm{D}_{2}\right)$ silkworms.

Table 7. Efficiency of conversion of IV and V instar bivoltine $\left(\mathrm{NB}_{4} \mathrm{D}_{2}\right)$ silkworms treated with Kavach dusted twice.

\begin{tabular}{|c|c|c|c|c|c|c|c|}
\hline \multirow[t]{2}{*}{ Dosage } & \multicolumn{3}{|c|}{ IV instar } & \multicolumn{4}{|c|}{$V$ instar } \\
\hline & $1^{\text {st }}$ day & $2^{\text {nd }}$ day & $3^{\text {rd }}$ day & $2^{\text {nd }}$ day & $3^{\text {rd }}$ day & $4^{\text {th }}$ day & $5^{\text {th }}$ day \\
\hline 0.4 & 22.80 & 27.00 & 33.90 & 30.60 & 41.30 & 74.10 & 41.95 \\
\hline 1.0 & 24.15 & 29.10 & 35.65 & 33.10 & 43.10 & 49.10 & 44.00 \\
\hline 1.6 & 21.90 & 27.30 & 32.15 & 29.90 & 41.00 & 46.30 & 41.25 \\
\hline Control & 24.60 & 29.20 & 36.00 & 33.25 & 43.50 & 49.20 & 44.40 \\
\hline $\mathrm{SE}( \pm)$ & 0.364 & 0.439 & 0.538 & 0.807 & 0.659 & 0.748 & 0.669 \\
\hline CD@ @ $5 \%$ & 0.953 & 1.148 & 1.406 & 2.109 & 1.723 & 1.955 & 1.752 \\
\hline
\end{tabular}

Table 8. Growth rate of IV and V instar bivoltine $\left(\mathrm{NB}_{4} \mathrm{D}_{2}\right)$ silkworms treated with Kavach dusted twice.

\begin{tabular}{|c|c|c|c|c|c|c|c|}
\hline \multirow[t]{2}{*}{$\overline{\text { Dosage }}$} & \multicolumn{3}{|c|}{ IV instar } & \multicolumn{4}{|c|}{$\mathrm{V}$ instar } \\
\hline & $1^{\text {st }}$ day & $2^{\text {nd }}$ day & $3^{\text {rd }}$ day & $2^{\text {nd }}$ day & $3^{\text {rd }}$ day & $4^{\text {th }}$ day & $5^{\text {th }}$ day \\
\hline 0.4 & 29.10 & 32.80 & 36.91 & 26.90 & 33.25 & 54.00 & 44.85 \\
\hline 1.0 & 31.00 & 34.30 & 38.90 & 29.00 & 35.00 & 57.00 & 45.70 \\
\hline 1.6 & 28.40 & 31.80 & 35.90 & 25.95 & 33.10 & 54.08 & 43.15 \\
\hline Control & 31.50 & 34.50 & 39.05 & 29.50 & 35.60 & 57.60 & 47.00 \\
\hline $\mathrm{SE}( \pm)$ & 0.468 & 0.520 & 0.588 & 0.590 & 0.534 & 0.683 & 0.631 \\
\hline $\mathrm{CD} @ 5 \%$ & 1.224 & 1.361 & 1.538 & 1.544 & 1.397 & 1.786 & 1.649 \\
\hline
\end{tabular}

both the races, total soluble sugar increases linearly from third day till fifth day in infected races. In control worms, sugar level considerably decreased in healthy larvae from third day till fifth day. Analysis of variation is increasing in total soluble sugar is due to degradation of carbohydrate by developing pathogen and end product of carbohydrate metabolism are liberated as per the report of Raghavaiah and Jayaramaiah (1989).

Physiology of silkworm: Kavach treated silkworm races, showed variable quantity of food ingested during IV and V instars. Kavach (dusted twice) treated bivoltine silkworm larvae indicated maximum food ingestion on third day $(7.35 \mathrm{~g})$ of IV instar and fourth day $(30.15 \mathrm{~g})$ of $\mathrm{V}$ instar at $1.0 \%$. Noticeable decreases in food intake at lethal doses as well as a moderate increase in food intake at sub-lethal doses were observed. It is clear from the results that, sub-lethal doses of fungicide seem to stimulate larvae to consume more food. Lower doses of fungicide may also act as attractants to silkworms for consuming more food. At lethal doses, same fungicide may have acted as repellent, resulting in less food consumption. At low concentrations, fungicide is expected to be extracted in feaces and urine within 24hours, where as at higher concentrations, it gets metabolized and joins main stream of haemolymph (Kusunoki and Watanabe, 1982). Bivoltine silkworm larvae in both IV and V instars treated with Kavach at $1 \%$ showed maximum food conversion $(22.60 \%)$, efficiency of conversion of digested food was found to be highest (49.10\%) and maximum growth rate $(57.00 \%)$ on fourth day of $\mathrm{V}$ instar at $1 \%$ (Tables 5-8). Present findings are in conformity with Ueda and Lizuka (1962) who demonstrated that, silkworms were more sensitive to environmental conditions and fungicides. They considered rate of ingestion and conversion efficiency as better parameters of metabolic rates. Secretion of digestive enzyme is dependent on quantum of food ingested into body because the presence of food may 
act as a stimulus for secretion of enzymes. Study of the pattern of distribution of food in digestive tract of B. mori has led to conclusion that, silkworms feed continuously. Larval growth percentage depends on nutrients absorbed by intestine, consumed directly for silkworms life and other parts are presented in larval body to increase weight and body volume, thus larval growth takes place. Kavach dusted twice at $1 \%$ proved to be very useful and various commercial characters like cocoon weight, shell weight, shell percentage, filament length, renditta and denier showed beneficial results over the control worms (Tables 1 and 2). Isaiarasu et al. (2011) revealed that, aqueous and alcoholic crude extracts of three herbs such as $A$. indica, $O$. sanctum and $T$. procumbens are effective against microbes causing flacherie and muscardine diseases in silkworm. Alcoholic extracts were generally more effective than aqueous extracts that helps in disease resistance and silk production. Kumari et al. (2011) aimed at investigation effect of dichloromethane and methanol (1:1) extract of seaweed brown algae, $T$. conoides for its antifungal activity against $B$. bassiana. Three different concentrations of this algal extract were tested against $B$. bassiana infected silkworm larvae and effective concentration was evaluated between 1000 to $1500 \mu \mathrm{g}$ $\mathrm{mL}^{-1}$ of the algal extracts. It was established that, with the application of these algal extract about $75 \%-85 \%$ of larval mortality due to $B$. bassiana infection was controlled without affecting other qualitative and quantitative traits. Chavan et al. (2011) reported that, use of plant based drugs and chemicals for curing various ailments and personal adornment is as old as human civilization. Aqueous extracts of A. mexicana, T. arjuna, S. cumini and A. squamosa were tested for antifungal activity invitro and study revealed that, aqueous extract of $A$. mexicana shows effective results on $B$. bassiana infected B. mori larvae as compared to other botanicals. However it is clear that, aqueous plant extracts showed decreased mortality with effective rate of rearing. Kumar et al. (2011) demonstrated that, four systemic fungicides Bavistin, Bayleton, Dithane $\mathrm{M}_{45}$ and Thiram were tested for efficacy to control white muscardine in A. mylitta D. Bavistin and Dithane $\mathrm{M}_{45}$ with $1 \%-2 \%$, Bayleton $0.15 \%-2 \%$ and Thiram $2 \%$ concentrations were found more effective among tested systemic fungicides in suppressing muscardine in tasar silkworm.

\section{Conclusion}

Present study concluded that, application of Kavach a potent fungicide encounter the pathogen by forming a thin layer on silkworm B. mori body and deactivates the function of $B$. bassiana fungus. It has been observed from the investigation that, moderate dosage (1\%) of Kavach could prevent worms from the incidence of muscardine. Food ingestion, digestion and conversion rate is greatly enhanced at $1 \%$ Kavach application. Cross breed silkworms showed better resistance compared to bivoltine silkworms and dusting of Kavach twice during IV and $\mathrm{V}$ instar exhibited better commercial characters in both the silkworm races.

\section{REFERENCES}

Ahmed, S.A. and Rajan, R.K. (2011). Exploration of Vanya silk biodiversity in north eastern region of India: Sustainable livelihood and poverty alleviation. Proceedings of the International Conference on Management, Economics and Social Sciences, (MESS' 11), Bangkok. pp. 485-489.

Anitha Peter, (1989). Investigation on the Aspergillosis of mulberry silkworm with special reference to its control. M.Sc. (Seri) Thesis, UAS, Bangalore, India. pp. 62-64.

Anitha, R. (2011). Indian silk industry in the global scenario. EXCEL International Journal of Multidisciplinary Management Studies, 1(3):100-110.

Baig, M., Samson, M.V., Sharma, S.D., Balavenkatasubbaiah, M., Sasidharan, T.O. and Jolly, M.S. (1993). Efficacy of certain bed disinfectants in different combination against the nuclear polyhedrosis and white muscardine diseases of silkworm Bombyx mori L. Sericologia, 33(1):53-60.

Benchamin, K.V. and Nagaraj, C.S. (1987). Silkworm rearing techniques. In: Appropriate sericulture techniques. (ed.) Jolly, M.S. Chapter-4, Mysore, India. pp. 63-106.

Chandrasekaran, K. and Nataraju, B. (2008). Studies on white muscardine disease of mulberry silkworm, Bombyx mori L. in India-A review. Indian J. Seric., 47 (2):136-154.

Chavan, J. A., Patil, S. J. and Bhawane, G.P. (2011). Screening of aqueous plant extracts against Beauveria bassiana infection to $5^{\text {th }}$ instar larvae of Bombyx mori $\mathrm{L}$. Journal of Medicinal Plants Research, 5(16):39363939.

Chinnaswamy, K.P. (1983). Studies on Aspergillosis of the silkworm Bombyx mori L. caused by Aspergillus tamari kita, M.Sc. (Agri.) Thesis, UAS, Bangalore, Karnataka. pp. 98.

Chinnaswamy, K.P. and Devaiah, M.C. (1986). Studies on the control of Aspergillosis of the silkworm Bombyx mori L. Indian J. Seric., 25:69-73.

Dandin, S.B. (2008). Large scale farming sericulture: A field reality. Indian Silk, 46:16-20.

Devaiah, M.C., Rajashekargowda, R. and Chinnaswamy, K.P. (1983). A new fungal pathogen, Aspergillus nidulans on the eri silkworm Samia cynthia ricini (Lepidoptera: Saturnidae). Indian J. Seric, 22: 71-72.

Isaiarasu, L., Sakthivel, N., Ravikumar, J. and Samuthiravelu, P. (2011). Effect of herbal extracts on the microbial pathogens causing flacherie and muscardine diseases in the mulberry silkworm Bombyx mori L. Journal of Bio pesticides, 4(2):150-155.

Kumar, K., K.P., Sinha, A.K., Singh, G.P. and Madhusudhan, K.N. (2011). Efficacy of Systemic Fungicides for Control of White Muscardine in Tasar Silkworm, Antheraea mylitta D. Research Journal of Microbiology, 6:805-812.

Kumari, S. S., Rao, S.V.S, Mishra, S. and Murthy, U.S. (2011). Antifungal activity of Turbinaria conoides and 
Evaluation for the effective concentration against the infection of Beauveria bassiana in silkworm larvae. Research Journal of Microbiology, 6(2):115-123.

Krishnaswami, S., Roy, D. and Mukherjee, S.K. (1970). Yield and nutritive value of mulberry leaves as influenced by planting system, spacing and frequency of pruning. Indian J. Seric, 9(1):38-42.

Krishnaswami, S. (1978). New technology of silkworm rearing. Bulletin No. 2, C.S.R. and T.I., Mysore, India. pp.1-20.

Krishnaswami, S. (1990). Improved method of rearing young age (chawki) silkworms. Bulletin No. 2, Central Silk Board, Bangalore, India. pp. 1-24.

Krishnaswami, S., Narashimanna, Suyananrayana, S.K. and Kumararaj, S. (1992). Sericulture Manual 2: Silkworm Rearing. Oxford and IBH, New Delhi.

Kusunoki, J. and Watanabe, H. (1982). Changes in the haemolymph $\mathrm{pH}$ and specific gravity of the silkworm larvae Bombyx mori infected with Beauveria bassiana. J. Seric. Sci. Japan, 51:447-448.

Lowry, O.H., Roseubrough, N.J., Ferr, L. and Randall, R.J. (1951). Protein measurement with the Folin-Phenol reagent. J. Biol. Chem, 193:265-275.

Nagaraju, J. (2008). Silk of India, grace and luster. Biotechnol. News, 3:4-7.

Patil, C.S. (1993). Review on Pebrine-a microsporidian disease in the silkworm, Bombyx mori L. Sericologia, 33:201-210.

Patil, C.S., Jyothi, N.B. and Dass, C.M.S. (2001). Silkworm faecal pellets examination as diagnostic method for detecting pebrine. Indian Silk, 39:11-12.

Pant, U., Sudeep, A.B., Athawale, S.S. and Vipat, V.C. (2002). Baculovirus studies in new indigenous lepidopteron cell lines. Indian J. Expt. Biol., 40(1):6368.

Plummer, D.T. (1971). An introduction to practical
Biochemistry, Tata McGraw Hill Publishing Company Ltd., Bombay and New Delhi, India.

Raghavaiah, G. and Jayaramaiah, M. (1989). Lethal concentration of white muscardine fungus Beauveria bassiana bals vuill to different races of mulberry silkworm. Indian J. Seric., 28(1):94-96.

Samson, M.V., Singh, R.N. and Sasidharan, T.O. (1998). Resham Jyothi-a wide spectrum bed disinfectant, Indian Silk, 37(3):9-10.

Seidavi, A., Bizhannia, A., Mawajpour, M., Mirhoseini, Z. and Ghanipoor, M. (2005). Investigation on necessity and methods of establishment of Sericultural cooperatives. Sericologia, 46:169-182.

Singhvi, N.R., Sharma, D.D. and Datta, R.K. (1996). Mulberry-a boon for social forestry. Indian Silk, 35:5152.

Soaf, K.A., Trag, A.R., Khan, M.A. and Chishti, M.Z. (1994). Evolution of fungicides against white muscardine disease of silkworm Bombyx mori L. caused by Beauveria bassiana bals vuill. J. Seric, 21(1\&2):1016.

Sonwalkar, T.N. (1991). Handbook of Silk Technology. Wiley Eastern Limited, New Delhi. pp. 25-48.

Subba Rao, G., Chandra, A.K. and Bhattacharya, J. (1992). Effect of bleaching powder and lime against grasserie and muscardine diseases of the silkworm Bombyx mori L. Indian J. Seric., 31:37-40.

Ueda, S. and Suzuki, K. (1962). Studies on the growth of silkworm Bombyx mori, chronological changes on the amount of food ingested and digested, body weight and water content of the body and their mutual relationship. Bull. Seric. Stn. Japan, 22:33-74.

Veeranna, G. (1999). Integrated silkworm disease management: China Vs India. Indian Silk, 38(3):27-28.

Waldbauer, G.P. (1968). The consumption and utilization of food by insects. Insect Physiol, 5:229-288. 